This is an author produced version of a paper published in EUPHYTICA. This paper has been peer-reviewed and is proof-corrected, but does not include the journal pagination.

Citation for the published paper:

Ninkovic, V \& Åhman, I. (2009) Aphid acceptance of Hordeum genotypes is affected by plant volatile exposure and is correlated with aphid growth. Euphytica. Volume: 169 Number: 2, pp 177-185. http://dx.doi.org/10.1007/s10681-009-9918-3

Access to the published version may require journal subscription. Published with permission from: Springer

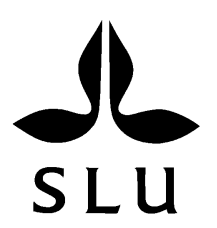

Epsilon Open Archive http://epsilon.slu.se 


\title{
Aphid acceptance of Hordeum genotypes is affected by plant volatile exposure and is correlated with aphid growth
}

\author{
Velemir Ninkovic $^{1 *}$ Inger M. Åhman $^{2}$ \\ ${ }^{1}$ Swedish University of Agricultural Sciences, Department of Ecology, P.O. Box 7044, SE-750 07 \\ Uppsala, Sweden, ${ }^{2}$ Swedish University of Agricultural Sciences, Faculty of Landscape Planning, \\ Horticulture and Agricultural Science, P.O. Box 44, SE-230 53 Alnarp, Sweden
}

\begin{abstract}
Nineteen genotypes of Hordeum vulgare were characterized as partially resistant or susceptible regarding growth of the bird cherry - oat aphid (Rhopalosiphum padi L.). These genotypes were treated with volatiles from undamaged plants of barley cultivar Alva. Aphid host acceptance (AHA) was significantly affected in seven genotypes, and the magnitude of the effect was positively correlated with aphid growth (AG) in a resistance screening test. Changes in AHA induced by volatiles from the same genotype were also positively correlated with AG. All genotypes were tested as inducers with cultivar Kara as the receiver of volatiles. Five genotypes induced significant reductions in AHA of Kara. The results show that aphids are able to detect changes in responding plants induced by volatiles from another cultivar. Plant volatile interactions may thus be a component of induced resistance to aphids. These interactions could influence the results of experiments used to select for insect-resistant plants in plant breeding programmes.
\end{abstract}

Keywords Rhopalosiphum padi, aphid, Hordeum, barley, allelobiosis, host resistance, plant breeding

*Corresponding author Velemir Ninkovic

Velemir.Ninkovic@ekol.slu.se

Tel. nr. +4618672541

Fax +46 18672890 


\section{Introduction}

In plant breeding it is essential that selection for desirable plant traits is made with high precision but a reasonable economical cost. In the case of breeding cereal plant resistance to aphids, success has been achieved with the greenbug, Schizaphis graminum Rondani, and the Russian wheat aphid, Diuraphis noxia Kurdj. Both these aphids cause easily detectable plant damage, and selections can be based on reduced symptoms (e.g. Berzonsky et al. 2003). In other aphid species that cause more subtle damage to cereals, such as the bird cherry - oat aphid (Rhopalosiphum padi L.), selections for resistance traits must be made by more laborious methods such as determination of aphid growth rate. Reduced nymphal growth rate, for example, is expected to result in smaller adults that have reduced fecundity (cf. Dewar 1977), a prolonged developmental period to adulthood or both these traits.

Bird cherry - oat aphids that invade cereals in the spring undergo several generations in the crop before it starts maturing. Crop characteristics that slow the aphid growth rate may thus influence successive generations and have profound effects on population development. Wiktelius and Pettersson (1985) estimated that a simulated $20 \%$ reduction in aphid fecundity leads to a $40 \%$ reduction in peak aphid numbers. A low aphid growth rate may be caused by certain physical or chemical plant traits that directly affect aphid host acceptance and feeding behaviour (Pettersson et al. 2007). Alternatively, poor aphid growth can be a result of poor food quality due to plant toxins or an imbalanced nutrient composition. Thus, when determination of plant resistance is based on aphid growth measurements alone it is not obvious whether antixenosis, insect behavioural responses to host resistance characteristics, or antibiosis, insect physiological responses, are causing the resistance (Smith 1989). The plant resistance characteristics can be constitutive, induced or both. Because $R$. padi is a cosmopolitan pest of cereals causing both direct and secondary damage as a vector of barley yellow dwarf virus (Blackman and Eastop 1984), attempts have been made to breed for resistance to this aphid (Weibull 1994; Åhman et al. 2000).

In an ongoing long term effort to breed for resistance to $R$. padi in barley, the selection method is based on measurements of aphid growth. In parallel studies, it has been shown that volatiles from undamaged barley plants can, in certain cultivar combinations, reduce $R$. padi acceptance of the volatile-exposed plants (Pettersson et al. 1999; Ninkovic et al. 2002). It has also been shown that exposure to volatiles from Cirsium spp. thistles can make the responding barley plants less acceptable to $R$. padi (Glinwood et al. 2004) and more attractive to predatory ladybirds (Ninkovic and Pettersson 2003). The phenomenon of multi-trophic relationships influenced by chemical interactions between undamaged plants has been termed allelobiosis (Ninkovic et al. 2006). That herbivore-damaged plants can induce resistance in neighbouring undamaged plants has been known for more than two decades (Baldwin et al. 2006), and R. padi is known to respond with lower acceptance of undamaged hosts exposed to 
volatiles from aphid-damaged hosts (Pettersson et al. 1996). The finding aphid host relations can be affected by volatile induction from undamaged and damaged plants led us to question whether this might affect the outcome of aphid resistance tests for plant breeding. When screening for resistance to pests and diseases for the purpose of selecting resistant plant genotypes, the common procedure is to grow different genotypes in greenhouses or climate chambers within a restricted area, in order to compare plants under similar environmental conditions (Smith 1989). This arrangement will, however, facilitate transfer of plant volatiles between plant individuals, introducing a further potential source of variation in the results.

In previous tests of plant volatile interactions in undamaged, cultivated barley, effects were detected in certain combinations of four barley genotypes, measured as changes in plant acceptance by $R$. padi (Ninkovic et al. 2002). The aim of the present study was to determine whether there is a relationship between $R$. padi growth rate on a certain genotype, measured by standard tests for aphid resistance, and changed aphid host acceptance of that genotype when previously exposed to volatiles from a another barley cultivar, or from the same cultivar. We investigated this in cultivated barley, H. vulgare ssp. vulgare, in its wild progenitor, $H$. vulgare ssp. spontaneum, and in breeding lines produced by crossing $H$. v. ssp. spontaneum and barley cultivars. Representatives of partially resistant genotypes as well as susceptible ones were included. We discuss the results with special emphasis on the fact that if volatile interactions between plants occur widely, they are a potential factor affecting the outcome of tests typically used to select for insect-resistant plants in breeding programmes.

\section{Materials and Methods}

Aphid cultures

Aphids were reared in two laboratories: at Svalöf Weibull AB (SW) in south Sweden (for aphid growth tests) and at the Swedish University of Agricultural Sciences (SLU) in Uppsala, central Sweden (for host acceptance tests). In Uppsala, the aphids were collected from a nearby barley field. At SW, aphid cultures were provisioned each spring with migrants from a tree of the winter host Prunus padus L. present in a nearby park. All aphids were reared on oats (Avena sativa L.), in cages in glasshouses at a temperature of $20 \pm 2{ }^{\circ} \mathrm{C}$ with minimum $16 \mathrm{hr}$ light (natural light supplemented by light from HQIE lamps). 
Plant material

The barley material consisted of three groups. The first contained ten Hordeum vulgare ssp. vulgare genotypes, including named European varieties and accessions from gene banks (for CI-numbers see http://www.ars-grin.gov/npgs/acc/acc queries.html and for BCC- and IG-numbers see http://barley.ipkgatersleben.de/ebdb.php3). The second contained six Hordeum vulgare ssp. spontaneum (H.sp.) collects. Within this group the aphid growth data for H.sp. 1, 3, 5 and 6 has previously been presented in another form by Åhman et al. (2000), whereas data for H.sp. IG 39759 and IG 40022 are reported here for the first time. All of the genotypes in these two groups were selected for further studies after aphid growth tests, to represent both susceptible and more resistant genotypes. A third group consisted of three doubled haploid (DH) lines. The DH lines, 5172-28:4, 5172-39:9 and 5175-50:20, all originate from a F1 DH line obtained from a cross between Lina and H.sp. 5. This line was back-crossed to cultivar Lina to produce 5172-28:4 and 5172-39:9, and back-crossed to cultivar Barke to produce 517550:20. These DH lines were selected for further studies because they caused greater reductions in aphid growth compared to their DH siblings. In addition, cultivars Alva and Kara were included in the studies because they have previously shown allelobiosis effects (Ninkovic et al. 2002).

Aphid growth

Aphid growth tests have been carried out over many years of screening barley genotypes for $R$. padi resistance (partly reported by Åhman et al. 2000). Seeds were germinated in Petri dishes on filter paper soaked with water containing $0.75 \% \mathrm{H}_{2} \mathrm{O}_{2}$ and were thereafter cold-treated in a refrigerator for three days. After a further 2-3 days at room temperature, the seedlings were planted in slow-release fertilized soil (1 dl of 15-4.8-10.8 N-P-K Osmocote Plus and $15 \mathrm{ml}$ of Multifritt minerals per 501 of Hammenhög's potting soil) in $10 \mathrm{~cm}$-diameter-pots. A cylindrical Perspex cage (diameter $2 \mathrm{~cm}$, length $5 \mathrm{~cm}$ ), was placed around the base of the plant allowing the seedling to grow through, and cotton wool was placed on the soil to seal the cage. One test plant of each genotype was placed in a plastic tray (41 x $62 \times 11 \mathrm{~cm}$ ), randomly positioned in each of four replicates. The trays were placed in a greenhouse and plants were grown at a temperature of $20 \pm 2{ }^{\circ} \mathrm{C}$ with minimum $16 \mathrm{hr}$ light (natural light supplemented by light from HQIE lamps). At the 2-3 leaf stage, five nymphs were introduced into each cage and the top sealed with cotton wool. The nymphs had been produced by alate aphids kept on oat plants for one day. In the majority of cases, tests were performed in a Conviron growth cabin (E15, CMP3244, 16L:8D at ca. $220 \mu \mathrm{mol}$ photons $/ \mathrm{m}^{2} \mathrm{sec}$ at plant level) at $22{ }^{\circ} \mathrm{C}$ for four days, after which the surviving aphids were weighed individually on a micro balance (Mettler M3). In the tests that are also presented in Åhman et al. (2000), temperatures, test duration, and aphid origins were varied to check for stability in results, and under all these conditions aphids reached a stage close to adulthood but did not start to reproduce. For the purpose of screening barley for resistance breeding, each test included 
additional plant material (22 genotypes per test in total). Since nymphal size at the start of the experiment varied between tests, aphid size on test genotypes was compared with that on Lina, which was a common cultivar in Sweden when the breeding programme started. The results on selected barley genotypes presented here originate from tests conducted between 1997 and 2006.

Plant exposure to plant volatiles

Exposure of one barley genotype to volatiles from another was made in a series of two-chamber cages (Pettersson et al. 1999; Ninkovic et al. 2002) in a glasshouse at SLU in Uppsala. Each cage consisted of two linked chambers (each $10 \times 10 \times 40 \mathrm{~cm}$ ); an emitter chamber (EC) and a receiver chamber (RC). An air flow (1.3 $\left.1 \mathrm{~min}^{-1}\right)$ entered EC and then RC via openings $(7 \mathrm{~cm}$ diameter), allowing air to first pass over a pot of plants in EC and then over a pot of plants in $\mathrm{RC}$, before being vented outside the glasshouse. Each pot was placed in a Petri dish to prevent plant interaction via root exudates. Individual pots were supplied with water from tubes connected to an automatic drop system (DGT Volmatic). Plants for the experiments were grown in a separate glasshouse compartment under the same light and temperature conditions as in the cage compartment, which was minimum $16 \mathrm{hr}$ of light at $18-22^{\circ} \mathrm{C}$. Natural light was supplemented by light from HQIE lamps. Germination of seeds was carried out as described above and six germinating seeds per pot were planted in $8 \times 8 \times 6 \mathrm{~cm}$ pots filled with soil (Hasselfors Garden Special). To minimize volatile interactions between genotypes during the preexposure period, pots with different genotypes were placed at least $1 \mathrm{~m}$ apart. At the beginning of the exposure period, plants were at the end of one-leaf stage. Exposure time was five days.

It has been shown that exposure to volatiles from cultivar Alva induces cultivar Kara to become less acceptable to R. padi in both laboratory and field experiments (Ninkovic et al. 2002). Accordingly, in our tests with other barley genotypes, we used Alva as a source of volatiles to which test genotypes were exposed in order to test their capacity to respond, and Kara as a receiver to test their capacity to induce. All genotypes were exposed to volatiles from cultivar Alva but, in a separate treatment, also to volatiles from the same genotype (self-induction) as well as to ambient air as a control treatment. Both the EC and the RC contained a single pot with six plants. In control treatments there were no plants in the EC. Five plants per plot in the RC were randomly selected for aphid host acceptance tests. Each of the three treatments (Alva-induction, self-induction and control) was represented by four pots arranged in four blocks, with random positions of treatments within the block. In tests of a genotype's capacity to induce, the cultivar Kara was exposed to volatiles from the test genotypes or an empty EC (control). 
Aphid host acceptance

Aphid acceptance of volatile-exposed plants was tested in a no-choice settling test (Ninkovic et al. 2002) at SLU in Uppsala. The fully developed second leaf of plants at the two leaf stage was placed in a transparent polystyrene tube (diameter $2.5 \mathrm{~cm}$, length $25 \mathrm{~cm}$ ). The upper end of the tube was sealed with nylon net and the lower end was plugged with plastic foam through which the leaf entered via a slit. The tube was attached to a wooden stick to support the plant. Ten mixed-instar apterous aphids were transferred from the rearing cage to the tube and the number of aphids settled (i.e. not walking) on the leaf was counted after $2 \mathrm{hr}$, since this is sufficient time for aphids to reach the phloem (Prado and Tjallingii 1997). The tests were done under the same conditions as for plant exposure but in a separate greenhouse compartment.

Statistical analyses

Mean aphid weight on each of the four test plants was determined based on the weights of 1-5 aphids, depending on how many were recovered on the plant. Whether aphid weight on a test genotype differed from that on the control cultivar Lina was tested in a two-factor ANOVA with plant genotype, test number and their interaction as factors. As a relative measurement of aphid growth, mean aphid weight for each plant genotype (mean from four plants) was divided by the corresponding mean aphid weight for the cultivar Lina (variable AG). For comparisons of aphid plant acceptance after volatile exposure, by Alva plants or plants from the same seed lot as the receiver, a two-factor ANOVA was performed with volatile treatment (emitting genotypes and ambient air), block and their interaction as factors, followed by Tukey's test if $\mathrm{F}$-values for genotype were significant at $\mathrm{p}<0.05$. Ratios were calculated to correct for possible minor differences in ambient conditions between different test occasions; one for the Alva- and another for the self-exposure; as mean number of aphids settled on plants exposed to volatiles from the emitter genotype divided by mean number of aphids on air-exposed control plants (variables of AHA). Neither variable was normally distributed, so Spearman's rank correlation statistic was used to test for a possible relationship between AG and AHA. Aphid host acceptance of Kara with each of the 19 genotypes as volatile emitters were compared to air controls by t-test. All statistical analyses were performed with the Statistica software (Statsoft Inc., 2005). 


\section{Results}

Aphid growth on different genotypes

The only $H . v$. vulgare genotypes that supported a significantly reduced aphid growth compared to that on Lina were BCC 38 and BCC 11 (Table 1). The CI lines were included in the test because they were earlier reported to give rise to few and small aphids (Hanson and Charpentier 1988), but they supported similar aphid growth rates as Lina in the current study. Among the H. v. spontaneum genotypes, IG 39759, IG 40022 and H.sp. 5 gave rise to significantly smaller aphids than Lina, as did all three breeding lines.

Aphid host acceptance and the effects of plant volatile exposure

Significantly fewer aphids accepted Kara or Alva that had been exposed to odours from Alva than airexposed Kara or Alva, respectively (Table 1). This is in line with previous studies (Pettersson et al. 1999; Ninkovic et al. 2002). Exposure to volatiles from Alva caused significantly reduced aphid acceptance in six other genotypes apart from Kara; Lina, CI 16145, BCC 11, H.sp. IG 40022, DH 5172-28:4 and DH 5175-50:20. In CI 11506, exposure led to significantly increased aphid acceptance. In addition to Alva, three other genotypes had significantly reduced aphid acceptance after exposure to plants of the same genotype; BCC 11, H.sp. IG 39759 and H.sp. 5. These three were also the genotypes with the lowest aphid growth rates relative to Lina. Only BCC 11 responded with changed aphid acceptance after exposure to both Alva and plants from the same seed lot.

Apart from Alva, volatiles from five other genotypes, Haisa, CI 1470, CI 11245, H.sp. 3 and H.sp. IG 40022, caused significantly reduced aphid acceptance of Kara (Table 1).

Relationship between aphid growth and acceptance of plants exposed to plant volatiles

There was a significant, positive correlation between relative aphid weights when reared on the barley genotypes and effects of plant-plant exposure in aphid acceptance tests, both after exposure to volatiles from Alva (Spearman's rank correlation coefficient $r_{s}=0.48, p=0.037$; Fig. 1a) and from the same genotype $\left(r_{s}=0.65, p=0.002\right.$; Fig. $\left.1 b\right)$. In general, genotypes which supported the lowest aphid growth rate exhibited the strongest reduction in aphid acceptance upon plant volatile exposure. 


\section{Discussion}

It has previously been shown that exposure of certain barley cultivars to volatiles from certain other barley cultivars affects subsequent host acceptance by $R$. padi (Pettersson et al. 1999; Ninkovic et al. 2002). Here we show that this phenomenon is not only present in more cultivars of barley but also in the wild ancestor of barley, Hordeum vulgare ssp. spontaneum, and breeding lines with such ancestry. From a technical viewpoint, our results may have consequences for the interpretation of results from tests typically used for selections of insect resistant plants in breeding programmes, and results from other studies of host related effects on feeding behaviour and performance of herbivorous insects. In both cases volatiles from neighbouring plants may induce changes in test plants that modify the outcome of such tests. We found that aphid growth in screening tests for resistance (measured by aphid weight) was positively correlated with aphid acceptance of barley genotypes after exposure to volatiles from Alva. This indicates that volatile interaction between plants may influence the results of screening barley genotypes for aphid resistance. We do not yet know whether the induced plant characteristics affect only host acceptance and feeding (antixenosis) and thereby reduce aphid growth, or whether there are induced plant responses directly affecting aphid physiology and growth (antibiosis). We are currently investigating this by rearing $R$. padi on the test plants under exposure to volatiles from cultivar Alva followed by detailed studies of aphid feeding behaviour using the EPG technique (cf. Prado and Tjallingii 2007) combined with gene transcriptional profiling after volatile induction.

In the present study of aphid growth, overall composition of barley genotypes varied between tests, since additional plant material was included for breeding purposes. A previous study has shown that changes in aphid plant acceptance occur only when certain barley cultivars are combined (Ninkovic et al. 2002). Thus, the relatively loose relationship between aphid growth in screening tests and aphid acceptance of Alva volatile-exposed plants might partly result from differences in the response of the tested genotypes induced by volatiles from Alva alone compared with induction by the complex mixture of volatiles from various barley genotypes in the aphid growth test chamber. The control variety in aphid growth tests, Lina, was itself responsive to induction by barley volatiles. Further, even though there was a positive correlation between the results on aphid growth and volatile induction, we do believe that genotype specific plant characteristics other than those induced by plant volatiles influence aphid growth on a particular host.

Exposure to volatiles from plants of the same genotype as the one tested for aphid acceptance resulted in an even stronger positive relationship between aphid growth and aphid acceptance than when Alva was used as volatile emitter. This may be partly explained by the fact that each of the 22 genotypes included in each aphid growth test was represented by four test plants. Thus, there was always the 
possibility of self induction by volatiles in the growth cabinet where these tests were performed, and those cultivars responsive to their own volatiles may then have expressed this in the growth test.

Interestingly, two of the three breeding lines, all with some Lina ancestry, were also significantly affected by Alva volatiles suggesting that it is possible to breed for allelobiotic effects. With our test cultivars for allelobiosis, Alva and Kara, there were seven cases of Alva inducing significant changes in aphid settling among the 19 tested barley genotypes and there were five cases in which the genotypes induced significant effects in the cultivar Kara. This suggests that the ability to induce other barley genotypes is as common as the ability to respond to such induction. However, more combinations of barley genotypes should be tested to confirm this. Only one of the 19 genotypes (IG 40022) was able both to induce another (Kara) and to be induced (by Alva), a frequency of combined abilities expected by chance. And in only one barley genotype was there an induced susceptibility rather than induced resistance. This was in the line CI 11506, which supported the second highest aphid growth.

Contradictory results from screenings for resistance to R. padi have been reported (Robinson 1965; Basedow 1987), and we found that the CI-lines selected as resistant by Hanson and Charpentier (1988) were not different from our susceptible control variety in the growth tests. Allelobiosis effects from surrounding genotypes in the tests is one possible reason for these inconsistencies, although there are also many other factors contributing to variation in the screening results (see Robinson 1965).

The nature of the volatile compound(s) inducing effects in responding barley genotypes is not known at present. However, genotype specific differences in volatile emissions from undamaged plants have been found in potato (Wang and Kays 2002), rice (Rapusas et al. 1996), cotton (Elzen et al. 1986) and pear (Scutareanu et al. 2003). A high genetic variability in volatile emissions from herbivore-damaged plants has also been shown in cotton (Loughrin et al. 1995) and maize (Degen et al. 2004; Gouinguené et al. 2001). In other plant-herbivore systems, various organic compounds produced in response to plant damage have been shown to affect plant defence and plant gene expression in neighbouring plants, deterring herbivores and attracting their natural enemies (Dicke et al. 2003; Baldwin et al. 2006). Two such compounds, methyl jasmonate and methyl salicylate cause reduced host acceptance by $R$. padi in barley, but with a different diurnal response pattern than allelobiosis induction as measured both by aphid responses and gene expressions (Ninkovic et al. 2003; Glinwood et al. 2007). Marker genes for salicylate regulation were not induced in barley plants after exposure to Alva.

In several studies of plant-plant volatile interaction, volatiles induced by herbivore attack have been shown to prime neighbouring plants for increased defence activation (Engleberth et al. 2004; Ton et al. 2007), or to directly induce defence reactions (Baldwin et al. 2006). In allelobiosis, the inducing plants 
are seemingly undamaged and there are no obvious ecological grounds for neighbour plants to eavesdrop on their neighbours' volatiles and respond with anti-herbivore defence. However, this type of chemical interaction may have another role for the responding plant, namely in preparing it for competition with the emitter plant. It was previously shown that a volatile responding barley cultivar changes its biomass allocation pattern, shifting biomass from above-ground structures to the roots (Ninkovic (2003). Furthermore, the leaf temperature of barley plants exposed to volatiles from certain other cultivars was significantly reduced compared with unexposed plants, indicating that plant volatiles may induce physiological changes in responding plants (Pettersson et al. 1999). Aphids have an intimate relationship with their host plant and are very sensitive to changes in plant quality (Pettersson et al. 2007). Thus it is possible that changed aphid plant acceptance results from aphid assessment of host plant status. If volatile exposure also negatively affects aphid performance (growth), this behavior would be adaptive as it would allow aphids to quickly detect changes in host quality and avoid settling.

The relationships between aphid growth in resistance tests and aphid host acceptance suggest that there is a volatile-inducible component affecting aphids on barley. Whether there are similarities in plant responses to this volatile induction and the previously reported affects of aphid feeding is yet to be shown. Previous $R$. padi infestation of the host plant can substantially reduce subsequent $R$. padi growth (Messina et al. 2002; Messina and Bloxham 2004) and defence-related proteins; endochitinase, glucanase (Forslund et al. 2000) and proteinase inhibitors (Casaretto and Corcuera 1998) are induced by $R$. padi feeding. In other plant-aphid combinations, genes involved in secondary metabolism, oxidative stress and signal transduction are up-regulated (Smith and Boyko 2007). Ongoing studies of $R$. padi-induced gene expression in barley show that genes involved in defence and signal transduction are involved, and it is possible that some or several of these affect aphid growth (Delp et al. unpublished).

Plant volatiles, both those from undamaged plants as tested here and those resulting from herbivore damage, may also play a role for the outcome of studies of host related effects on feeding behaviour and performance of other herbivorous insects. Our results emphasise the importance of recognizing plant-plant volatile interaction as a factor in plant breeding experiments carried out in greenhouses. Results may also apply to small-scale field tests, in which different plant genotypes are grown closely together. Indeed, a previous study has shown that certain effects of barley volatile interactions demonstrated in the greenhouse also appear under field conditions (Ninkovic et al. 2002). While it is unclear to what degree such interactions have influenced previous plant breeding efforts for $R$. padi resistance in barley, our study suggests that it is possible to exploit the responding or inducing capacity of barley genotypes in plant breeding, and also in new pest control methods using cultivar mixes of 
inducers and responders, or a responder cultivar in monoculture treated with formulations of active volatiles.

\section{Acknowledgements}

We thank Jan Pettersson who encouraged us to carry out this study. Yvonne Andersson, Helena Appelgren, Martin Kellner, Annhild Andersson and Elham Ahmed provided excellent technical support. Lisbeth Jonsson, Johanna Witzell, Robert Glinwood, Ulrika Ganeteg and Torgny Näsholm commented on previous versions of the manuscript. This work is part of the PlantComMistra programme, financed by the Swedish Foundation for Strategic Environmental Research (Mistra). The Swedish Research Council for Environment, Agricultural Sciences and Spatial Planning, Formas, also contributed funding. Svalöf Weibull AB is thanked for supplying breeding lines.

\section{References}

Baldwin IT, Halitschke R, Paschold A, von Dahl CC, Preston CA (2006) Volatile signaling in plantplant interactions: "talking trees" in the genomics era. Science 311:812-815

Basedow T (1987) Screening oat varieties for cereal aphid resistance in the field and in the laboratory: a comparison of results. IOBC/WPRS Bulletin 10/1:162-165

Berzonsky WA, Ding H, Haley C, Harris MO, Lamb RJ, Mckenzie RIH, Ohm HW, Patterson FL, Peairs FB, Porter DR, Ratcliffe RH, Shanower TG (2003) Breeding wheat for resistance to insects. Plant Breed. Rev. 22:221-296

Blackman RL, Eastop VF (1984) Aphids on the World's crops: An identification guide. John Wiley \& Sons, Chichester, 466 pp

Casaretto JA, Corcuera LJ (1998) Proteinase inhibitor accumulation in aphid-infested barley leaves. Phytochemistry 49:2279-2286

Degen T, Dillmann C, Marion-Poll F, Turlings TCJ (2004) High genetic variability of herbivoreinduced volatile emission within a broad range of maize inbred lines. Plant Physiol 135:1928-1938

Dewar AM (1977) Assessment of methods for testing varietal resistance to aphids in cereals. Ann Appl Biol 87:183-190 
Dicke M, Agrawal AA, Bruin J (2003) Plants talk, but are they deaf? Trends in Plant Science 8:403405

Elzen GW, Williams HJ, Vision SB (1986) Wind tunnel flight responses by hymenopterous parasitoid Campoletis sonorensis to cotton cultivars and lines. Entomol Exp Appl 42:285-289

Engleberth J, Alborn HT, Schmelz EA, Tumlinson JH (2004) Airborne signals prime plants against insect herbivore attack. P NATL ACAD SCI USA 101:1781-1787

Forslund K, Pettersson J, Bryngelsson T, Jonsson L, (2000) Aphid infestation induces PR-proteins differently in barley susceptible or resistant to the bird cherry-oat aphid (Rhopalosiphum padi). Physiol Plantarum 110:496-502

Glinwood R, Gradin T, Karpinska B, Ahmed E, Jonsson L, Ninkovic V (2007) Aphid acceptance of barley exposed to volatile phytochemicals differs between plants exposed in daylight and darkness. Plant Signaling Behavior 2:321-326

Glinwood R, Ninkovic V, Pettersson J, Ahmed E (2004) Barley exposed to aerial allelopathy from thistles (Cirsium spp.) became less acceptable to aphids. Ecol Entomol 29:188-195

Gouinguené S, Degen T, Turlings TCJ (2001) Variability in herbivore-induced odour emissions among maize cultivars and their wild ancestors (teosinte). Chemoecology 11:9-16

Hanson R, Charpentier R (1988) Screening for resistance to bird cherry-oat aphid (Rhopalosiphum padi) in spring barley. IOBC/WPRS Bulletin 11/3:37-38

Loughrin JH, Manukian A, Heath RR, Tumlinson JH (1995) Volatiles emitted by different cotton varieties damaged by feeding beet armyworm larvae. J Chem Ecol 21:1217-1227

Messina FJ, Bloxham AJ (2004) Plant resistance to the Russian wheat aphid: effects on a nontarget aphid and the role of induction. Can Entomol 136:129-137

Messina FJ, Taylor R, Karren ME (2002) Divergent responses of two cereal aphids to previous infestation of their host plant. Entomol Exp Appl 16:43-50 
Ninkovic V (2003) Volatile communication between barley plants affects biomass allocation. J Exp

Bot 54:1931-1939

Ninkovic V, Ahmed E, Glinwood R, Pettersson J (2003) Effects of two types of semiochemical on population development of the bird cherry oat aphid, Rhopalosiphum padi in a barley crop. Agr Forest Entomol 5:27-33

Ninkovic V, Glinwood R, Pettersson J (2006) Communication between undamaged plants by volatiles: the role of allelobiosis. In: F. Baluška, S. Mancuso, D. Volkmann (Eds.) Communication in Plants: Neuronal Aspects of Plant Life, Vol. 28, Springer-Verlag Berlin Heidelberg, pp. 421-434

Ninkovic V, Olsson U, Pettersson J (2002) Mixing barley cultivars affects aphid host plant acceptance in field experiments. Entomol Exp Appl 102:177-182

Ninkovic V, Pettersson, J (2003) Searching behaviour of sevenspotted ladybird, Coccinella septempunctata - effects of plant-plant odour interaction. Oikos 100:65-70

Pettersson J, Ninkovic V, Ahmed E (1999) Volatiles from different barley cultivars affect aphid acceptance of neighbouring plants. Acta agric Scand, Section B, Soil and Plant Science 49:152-157

Pettersson J, Quiroz A, Fahad AE (1996) Aphid antixenosis mediated by volatiles in cereals. Acta Agric Scand Sect B, Soil and Plant Sci. 46:135-140

Pettersson J, Tjallingii WF, Hardie J (2007) Host-plant selection and feeding. In van Emden H, Harrington R (eds) Aphids as crop pest, Vol. 4, CAB International, pp. 87-113

Prado E, Tjallingii WF (1997) Effects of previous infestation on sieve element acceptance by two aphids. Entomol Exp Appl 82:189-200

Prado E, Tjallingii WF (2007) Behavioral evidence for local reduced of aphid-infested resistance. J Insect Science 7. 48

Rapusas HR, Bottrell DG, Coll M (1996) Intraspecific variation in chemical attraction of rice to insect predators. Biol Control 6:396-400

Robinson AG (1965) Variability of resistance of barley varieties to the aphid Rhopalosiphum padi (L.) in different environments. Proc. XII Int. Congr. Ent., London 1964: 533 
Scutareanu P, Bruin J, Posthumus MA, Drukker B (2003) Constitutive and herbivore-induced volatiles in pear, alder and hawthorn trees. Chemoecology 13:63-74

Smith CM (1989) Plant resistance to insects - A fundamental approach. John Wiley \& Sons, Inc., New York, $286 \mathrm{pp}$

Smith CM, Boyko EV (2007) The molecular bases of plant resistance and defense responses to aphid feeding: current status. Entomol Exp Appl 122:1-16

Ton J, D’Alessandro M, Jourdie V, Jakab G, Karlen D, Held M, Mauch-Mani B, Turlings TCJ (2007)

Priming by airborne signals boosts direct and indirect resistance in maize. Plant J 49:16-26

Wang Y, Kays SJ (2002) Sweetpotato volatile chemistry in relation to sweetpotato weevil (Cylas formicarius) behavior. J Am Soc Hortic Sci 127:656-662

Weibull J (1994) Resistance to Rhopalosiphum padi L. (Homoptera: Aphididae) in Hordeum vulgare subsp. spontaneum and in hybrids with $H$. vulgare subsp. vulgare. Euphytica 78:97-101

Wiktelius S, Pettersson J (1985) Simulations of bird cherry-oat aphid population dynamics: tool for developing strategies for breeding aphid-resistant plants. Agric Ecosyst Environ 14:159-170

Åhman I, Tuvesson S, Johansson M (2000) Does indole alkaloid gramine confer resistance in barley to aphid Rhopalosiphum padi? J Chem Ecol 26:233-255 
Table 1. R. padi responses to barley genotypes selected to represent different origins and aphid resistance reactions. The genotypes are sorted in three groups according to subspecies, and within group according to aphid weight in growth tests. Results of cultivars Alva and Kara are also presented for comparisons. Aphid weight is measured after growth on the test genotype present in a group of various other barley genotypes. The mean weight of aphids on the test genotype is divided by the mean weight of aphids on the cultivar Lina, and the mean of those ratios are presented here. Volatile receiver reactions are measured as number of aphids settling on the genotype after exposure to volatiles from the cultivar Alva, from the same genotype, or to air alone. Volatile emitter effects are measured as number of aphids settling on Kara after exposure to volatiles from the test genotype or air alone. 


\begin{tabular}{|c|c|c|c|c|c|c|c|c|c|}
\hline \multirow[t]{2}{*}{ Hordeum type } & \multirow[t]{2}{*}{ Test genotype } & $\begin{array}{l}\text { Aphid growth } \\
\text { (AG) }\end{array}$ & \multicolumn{4}{|c|}{$\begin{array}{c}\text { Aphid host acceptance (AHA) } \\
\text { of test genotype after volatile exposure }\end{array}$} & \multicolumn{3}{|c|}{$\begin{array}{c}\text { Aphid host acceptance (AHA) } \\
\text { of Kara after volatile exposure to } \\
\text { test genotype }\end{array}$} \\
\hline & & $\begin{array}{l}\text { Weight } \\
\text { relative to } \\
\text { Lina (n) }\end{array}$ & $\begin{array}{l}\text { Exposed to } \\
\text { Alva }\end{array}$ & Self-exposed & Air-exposed & $p$ & $\begin{array}{l}\text { Exposed } \\
\text { Kara }\end{array}$ & $\begin{array}{l}\text { Air- } \\
\text { exposed } \\
\text { Kara }\end{array}$ & $p$ \\
\hline \multirow[t]{12}{*}{ H. v. vulgare } & Alva & 1.031 & & $6.52^{b}$ & $7.94^{\mathrm{a}}$ & ${ }^{* *} \mathrm{SI}$ & 6.25 & 7.60 & ** \\
\hline & Kara & 1.090 & $6.25^{b}$ & $7.25^{\mathrm{a}}$ & $7.60^{\mathrm{a}}$ & ${ }^{* *} \mathrm{Al}$ & - & - & \\
\hline & Scarlett & 1.175 & $6.60^{\mathrm{b}}$ & $7.90^{\mathrm{a}}$ & $7.35^{\mathrm{ab}}$ & * & 7.35 & 7.35 & \\
\hline & $\mathrm{Cl} 11506$ & 1.136 & $7.50^{\mathrm{a}}$ & $6.60^{\mathrm{ab}}$ & $6.05^{b}$ & ${ }^{*} \mathrm{Al}$ & 7.00 & 7.80 & \\
\hline & $\mathrm{Cl} 11245$ & 1.037 & 7.90 & 8.30 & 7.85 & & 6.55 & 7.80 & ** \\
\hline & Haisa & 1.036 & 6.25 & 6.60 & 7.20 & & 7.05 & 8.10 & ** \\
\hline & Barke & 1.035 & 6.79 & 7.38 & 7.17 & & 6.50 & 7.30 & \\
\hline & Lina & 1.000 & $5.75^{b}$ & $7.58^{\mathrm{a}}$ & $7.38^{\mathrm{a}}$ & ${ }^{* \star} \mathrm{Al}$ & 7.70 & 8.10 & \\
\hline & $\mathrm{Cl} 16145$ & 0.980 & $5.05^{b}$ & $6.00^{\mathrm{ab}}$ & $6.50^{\mathrm{a}}$ & ${ }^{* *} \mathrm{Al}$ & 7.20 & 6.70 & \\
\hline & Cl 1470 & 0.924 & 7.15 & 7.05 & 6.75 & & 6.20 & 7.80 & $\star \star \star$ \\
\hline & BCC 38 & 0.822 * & 6.95 & 7.05 & 6.90 & & 6.80 & 7.35 & \\
\hline & $\mathrm{BCC} 11$ & $0.651^{* *}(3)$ & $6.00^{b}$ & $6.38^{b}$ & $7.92^{\mathrm{a}}$ & ${ }^{* * *} \mathrm{Al} \mathrm{SI}$ & 6.90 & 7.35 & \\
\hline \multirow[t]{6}{*}{ H. v. spontaneum } & H.sp. 3 & 1.013 & 6.60 & 6.35 & 7.05 & & 6.65 & 7.80 & * \\
\hline & H.sp. 1 & $0.997 \quad(9)$ & 7.00 & 7.95 & 7.50 & & 6.90 & 7.85 & \\
\hline & H.sp. 6 & 0.895 & 7.05 & 6.70 & 7.15 & & 7.30 & 7.60 & \\
\hline & H.sp. IG 40022 & $0.683^{* *}(3)$ & $6.20^{b}$ & $7.00^{\mathrm{ab}}$ & $7.90^{\mathrm{a}}$ & ${ }^{* *} \mathrm{Al}$ & 6.25 & 7.80 & ** \\
\hline & H.sp. IG 39759 & $0.666^{* *}(3)$ & $7.15^{\mathrm{ab}}$ & $6.15^{b}$ & $8.15^{\mathrm{a}}$ & ${ }^{* * *} \mathrm{SI}$ & 7.25 & 7.85 & \\
\hline & H.sp. 5 & $0.571^{* * *}(25)$ & $5.25^{\mathrm{ab}}$ & $4.55^{b}$ & $6.20^{\mathrm{a}}$ & ${ }^{*} \mathrm{SI}$ & 6.80 & 7.60 & \\
\hline \multirow[t]{3}{*}{ Breeding line } & $5172-28: 4$ & $0.846^{*} \quad(4)$ & $6.60^{\mathrm{b}}$ & $8.30^{a}$ & $8.35^{\mathrm{a}}$ & ${ }^{* \star \star} \mathrm{Al}$ & 7.55 & 8.10 & \\
\hline & $5175-50: 20$ & $0.801^{* *}(4)$ & $5.35^{b}$ & $7.10^{\mathrm{a}}$ & $6.75^{\mathrm{a}}$ & ${ }^{*} \mathrm{Al}$ & 7.40 & 7.30 & \\
\hline & $5172-39: 9$ & $0.779^{* *}(4)$ & 7.30 & 8.15 & 8.25 & & 7.81 & 7.86 & \\
\hline
\end{tabular}

(n) number of aphid growth tests

$*^{* * * * *}$ ANOVA result for "treatment" significantly different at $p<0.05,0.01,0.001$, respectively

${ }^{a . b}$ Means followed by a different letter are significantly different according to Tukey's test

(AI) Alva-induced. (SI) self-induced 


\section{Figure legends}

Fig.1a Relationship between aphid growth relative to the control Lina (AG) and aphid host acceptance of Alva-exposed plants relative to air-exposed plants (AHA). $r_{s}=0.48 . p=0.037(n=19)$.

Fig.1b Relationship between aphid growth relative to the control Lina (AG) and aphid host plant acceptance of self-exposed plants relative to air-exposed plants (AHA). $r_{s}=0.65 . p=0.002(n=19)$. 
Fig 1a

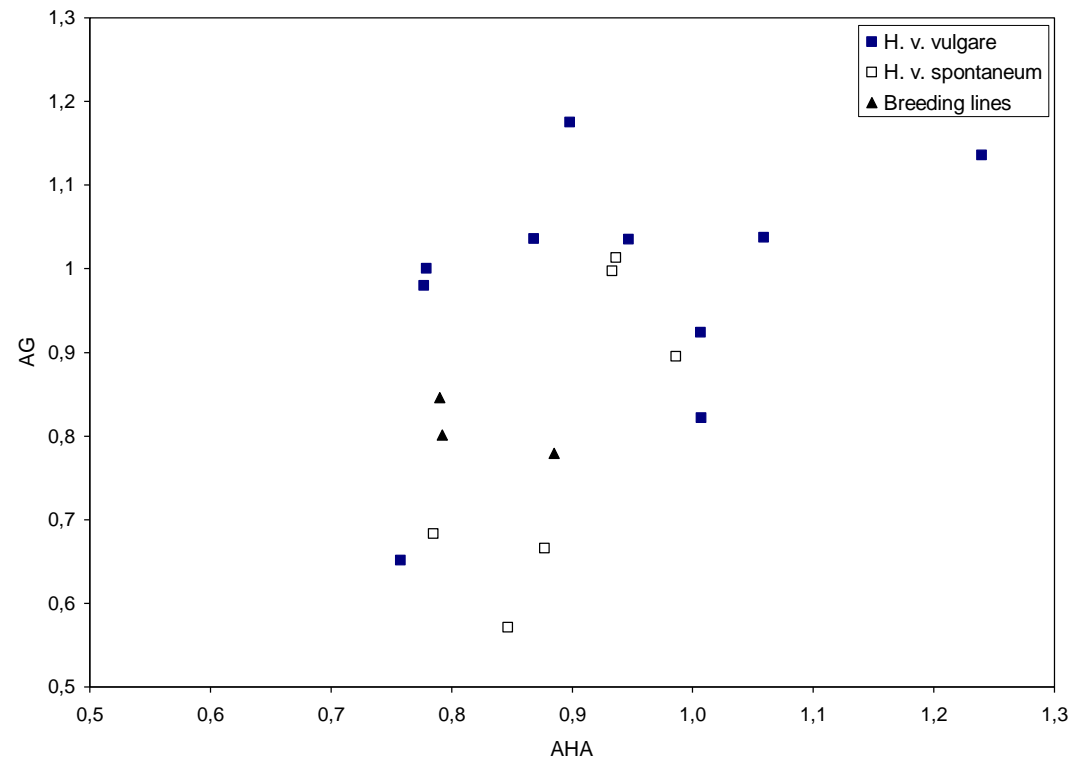


Fig 1b

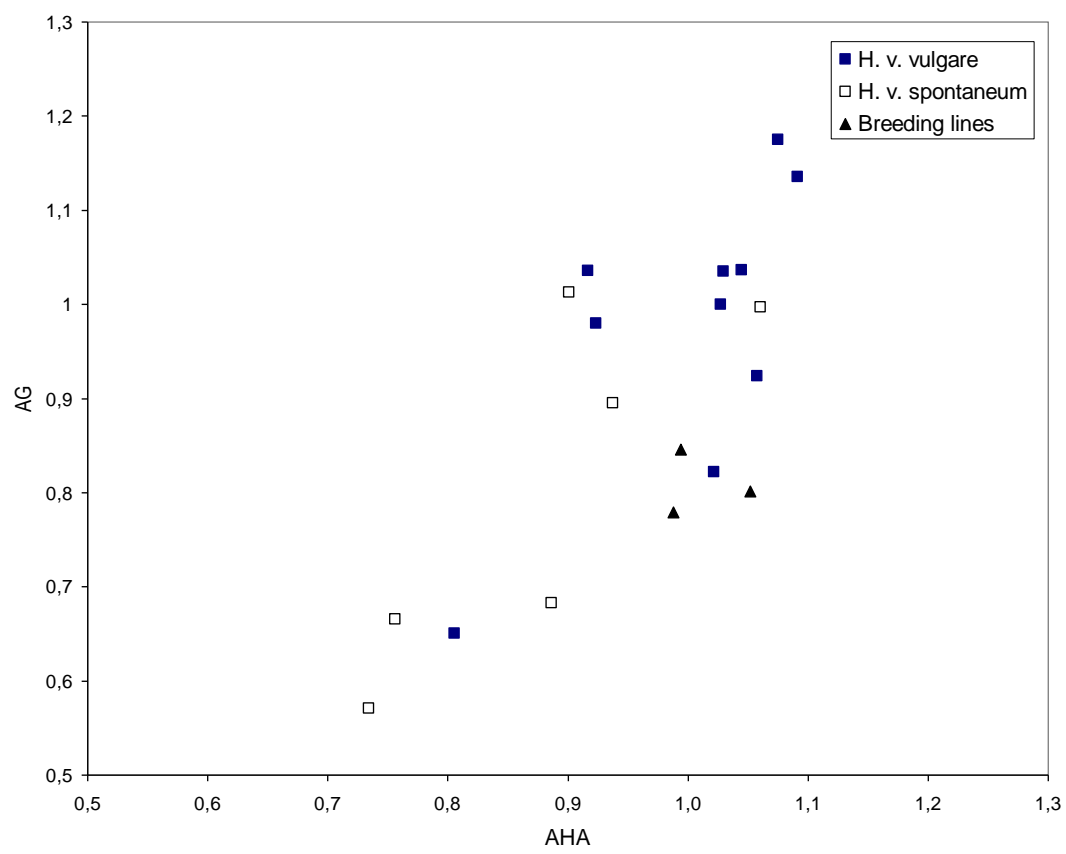

